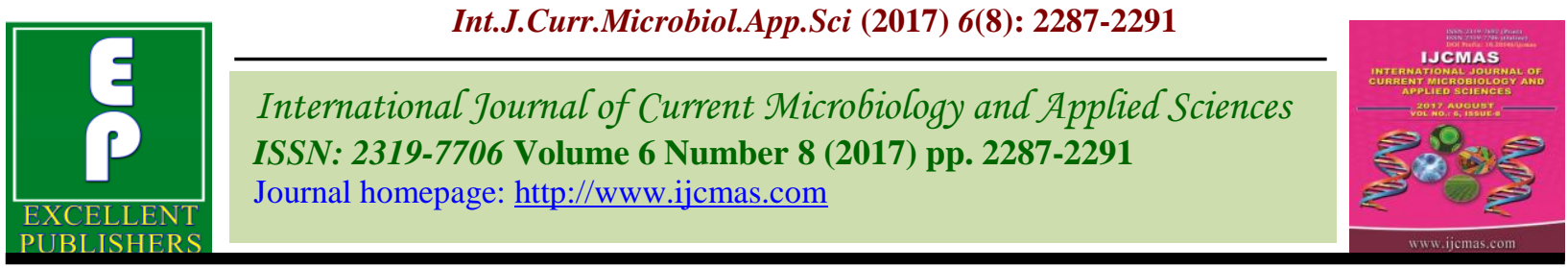

Original Research Article

https://doi.org/10.20546/ijcmas.2017.608.268

\title{
Efficacy of Different Bio Control Agents against Meloidogyne incognita and Fusarium oxysporum on Black gram (Vigna mungo L)
}

\author{
Dilip Kumar*, Jayant Bhatt and Ratan Lal Sharma \\ Department of Plant Pathology, College of Agriculture, Jawaharlal Nehru Krishi Vishwa \\ Vidyalaya Jabalpur, MP- 482004, India \\ *Corresponding author
}

A B S T R A C T

\begin{tabular}{|c|}
\hline Keywords \\
\hline $\begin{array}{l}\text { Fusarium } \\
\text { oxysporum, } \\
\text { Meloidogyne } \\
\text { incognita, Black } \\
\text { gram, Bio control } \\
\text { agents. }\end{array}$ \\
\hline Article Info \\
\hline $\begin{array}{l}\text { Accepted: } \\
21 \text { June } 2017 \\
\text { Available Online: } \\
10 \text { August } 2017\end{array}$ \\
\hline
\end{tabular}

\section{Introduction}

Black gram (Vigna mungo L), one of the pulses, is mostly produced in Asian countries as their tropical climate and soil type suits its cultivation. India occupies 31 lakh hectares of land with 14 lakh tones production and $451.61 \mathrm{~kg} / \mathrm{ha}$ productivity. Madhya Pradesh alone contributes 4.72 lakh hectares of land with 1.66 tones production and $351.69 \mathrm{~kg} / \mathrm{ha}$ productivity (Anon., 2012). Meloidogyne incognita is considered to be one of the most severe pests of blackgram. The nematodes adversely affect nodulation Nitrogen fixation and yield (Hussaini and Seshadri, 1975). Meloidogyne infection, which primarily impairs water and nutrient uptake, and upward translocation by the root system (Karssen and Moens, 2006). Meloidogyne incognita has evolved a specialized adoptive mechanism with the vascular wilt fungus $F$. oxysporum to cause a disease complex etiology in a variety of crop plants (Powell, 1971; Mai and Abawi, 1987). Such a disease complex, involving both the organisms has also been reported in black gram inflicting an appreciable loss in yield to the tune of 49 percent (Mahapatra and Swain, 1999). Application of biological control agents (BCA) is a promising and ecofriendly tool in 
improving current levels of agricultural production. It assists in reducing use of chemical pesticides thereby controlling release of their residues into environment. One of the most efficient ways to achieve this objective is to develop BCAs for disease control alone, or to integrate it with reduced doses of chemicals in the control of phytopathogens resulting in minimal impact of chemicals on the environment. If complexities exist between the two organisms, application of either a fungicide or a nematicide alone will reduce the respective pathogen only. More over extensive use of chemicals have adverse effect on the environment (Latha et al., 2000).

\section{Materials and Methods}

The experiment was conducted in ten $\mathrm{cm}$ earthen pots containing $500 \mathrm{~cm}$ sterilized soil employing five bio-control agents viz, Trichoderma viride, Paecilomyces lilacinus, Psuedomonas fluorescens, Bacillus subtilis and Pochonia chlamydosporia. The fungus $P$. lilacinus and $T$. viride were isolated from the soils of J.N.K.V.V Jabalpur from by sprinkling it on Petri plates containing sterilized Potato Dextrose Agar (PDA) medium. Both the organisms were purified and maintained on PDA plants. The fungus $T$. viride was multiplied on wheat seeds. The seeds were boiled in water for half an hour and excess moisture was drained out. The boiled seeds were filled in polypropylene bags @ 500g seeds per bag and autoclaved at $1.05 \mathrm{~kg} / \mathrm{cm}^{2}$ for 20 minutes. After cooling the bags were inoculated with pure culture of $T$. viride and inoculated at $24^{\circ} \mathrm{C}$ for 10 days. When sufficient growth was achieved the seeds along with fungus were mixed with the pot soil @ 2g/pot. Before mixing the fungus spore load was calculated by haemocytometer. Paecilomyces lilacinus was mass multiplied on wheat seeds following the technique described earlier and at maximum growth and spore load mixed with the pot soil
@ 2g per pot. Commercial formulations of Pochonia chlamydosporia, Psuedomonas fluorescence and Bacillus subtilis were obtained from Department of Nematology, Tamil Nadu Agricultural University with a spore load $2 \times 10^{7}$ colony forming units (cfu). These formulations were mixed with the pot soil @ 2g/pot. After mixing the test bioagents in to the soil infested with $F$. oxysporum the pot soil was sprayed by freshly hatched and surface sterilized second stage juveniles of $M$. incognita. The population of root-knot nematode $\left(2 \mathrm{j}_{2} / \mathrm{g}\right.$ soil $)$ was determined by the method described earlier. The soil with test bioagents and $M$. incognita was filled in ten $\mathrm{cm}$ earthen pots and sown with blackgram seeds. Each treatment was replicated five times and randomized on glass house earlier. The experiment was terminated 45 days after inoculation and observations on plant height, root length, shoot weight (fresh and dry), root weight (fresh and dry), number of galls, and nematode population in soil and roots were recorded.

\section{Results and Discussion}

The five biocontrol agents viz; Trichoderma viride, Pochonia chlamydosporia, Paecilomyces lilacinus, Bacillus subtilis and Pseudomonas fluorescense were tested against disease complex produced by $M$. incognita and $F$. oxysporum in black gram and the data is presented in table 1. All the treatments reduced incidence of nematode and fungus on growth of black gram and multiplication of nematode. The data presented in table 1 revealed that maximum plant height $(19.02 \mathrm{~cm})$ was recorded with Paecilomyces lilacinus followed by Pochonia chlamydosporia $(17.70 \mathrm{~cm})$, Trichoderma viride $(16.46 \mathrm{~cm})$, Bacillus subtilis $(15.68 \mathrm{~cm})$ and Pseudomonas fluorescence $(13.96 \mathrm{~cm})$. Inoculated control recorded minimum (11.10 $\mathrm{cm})$ plant height. Similarly maximum (18.38 $\mathrm{cm})$ root length was noted with $P$. lilacinus and minimum $(11.24 \mathrm{~cm})$ with control rest of 
the treatments were significantly superior over control but inferior over $P$. lilacinus, $P$. chlamydosporia, T. viride, B. subtilis and $P$. fluorescence which recorded 16.66, 15.44, 11.78 and $15.12 \mathrm{~cm}$ lengths respectively the effect of $P$. fluorescence and $T$. viride remained at par with each other.

Significantly increased fresh weight of shoot $(0.89 \mathrm{~g})$ was recorded with $P$. lilacinus which remained almost at par with $P$. chlamydosporia $(0.87 \mathrm{~g})$ and $T$. viride $(0.85)$, $B$. subtilis and $P$. fluorescence recorded 0.78 and $0.69 \mathrm{~g}$ shoot weight respectively against minimum $(0.62 \mathrm{~g})$ in control. Maximum $(0.86 \mathrm{~g})$ root weight on fresh weight basis was noted with $P$. lilacinus and $P$. chlamydosporia $(0.85 \mathrm{~g})$ which remained at par with each other. This treatment was followed by $T$. viride $(0.81 \mathrm{~g}), B$. subtilis $(0.76 \mathrm{~g})$ and $P$. fluorescence $(0.64 \mathrm{~g})$ Minimum root weight was recorded with inoculated control $(0.32 \mathrm{~g})$. Dry weight of shoot was significantly increased $(0.41 \mathrm{~g})$ in $P$. lilacinus against minimum $(0.26 \mathrm{~g})$ in control. The effect of $P$. chlamydosporia and $T$. viride remained at par with each other. These treatments recorded 0.38 and $0.36 \mathrm{~g}$ root weights respectively. Significantly lower shoot weights were recorded in $B$. subtilis $(0.33 \mathrm{~g})$ and $P$. fluorescence $(0.29 \mathrm{~g})$ but superior over inoculated control. All the treatments have significantly increased dry root weight of black gram. Maximum $(0.39 \mathrm{~g})$ dry root weight was recorded with $P$. lilacinus followed by $P$. chlamydosporia $(0.36 \mathrm{~g})$ and $T$. viride $(0.34 \mathrm{~g}), B$. subtilis and $P$. fluorescence recorded 0.32 and $0.28 \mathrm{~g}$ dry root weight respectively. Minimum $(0.25 \mathrm{~g})$ dry root weight was recorded in inoculated control. Minimum number (8.20) of galls were recorded in $P$. lilacinus followed by $P$. chlamydosporia (9.80) and T. viride (10.40), B. subtilis recorded 12.20 and $P$. fluorescence recorded 11.00 galls/plant respectively with maximum (13.80) galling in inoculated control. Maximum (1890.20) nematode recovery was noted in inoculated control. Which was significantly reduced in $T$. viride (1178.60) followed by $P$. chlamydosporia (1156.40) and P. lilacinus (1115.4). B. subtilis and $P$. fluorescence recorded 1230.40 and 1342.40 nematode (Root+ Soil).

The data presented in table 1 indicated that Paecilomyces lilacinus significantly increased the growth parameters of the blackgram viz., plant height, root length, fresh and dry weight of shoot and roots with significant decrease in the number of galls and final nematode population. These results are in accord with the finding of Latha et al., (2000) who observed increase in growth parameter and decrease in nematode multiplication of Hetrodera cajani in presence of Macrophomina phaseolina on Vigna mungo. Similar results have also been observed by Verma et al; (2005). On P. Iilacinus has been reported to produce peptidal antibiotic viz; lilacin and paecilotixin that are toxic to root knot nematode (Verma et al., (2005).

The biocontrol agent Pochionia chlamydosporia was also noted to be superior and took second rank in improving the plant growth and reduced nematode population. Similar finding have also been reported by Siddiqui and Mahmood on pigeon pea in the presence of Hetirodera cajani and Fusarium udum. Bacillus subtilis, and Psueudomonas fluorescens showed its efficacy in reducing the nematode population and enhancing the growth characters of the blackgram. These findings have also been supported by the result shown by Siddiqui and Mohmood (1995) on chickpea with $M$. incoginita and $M$. phaseolina. Poornima et al., (2007) on banana with Fusarium oxysporum and Helicotylenchus multicinctus, Latha et al., (2000) on blackgram, Haseeb et al., (2005) on green gram and Akhtar et al., (2012) on blackgram. 
Table.1 Efficacy of different biocontrol agents Meloidogyne incognita and Fusarium oxysporum on plant growth parameters

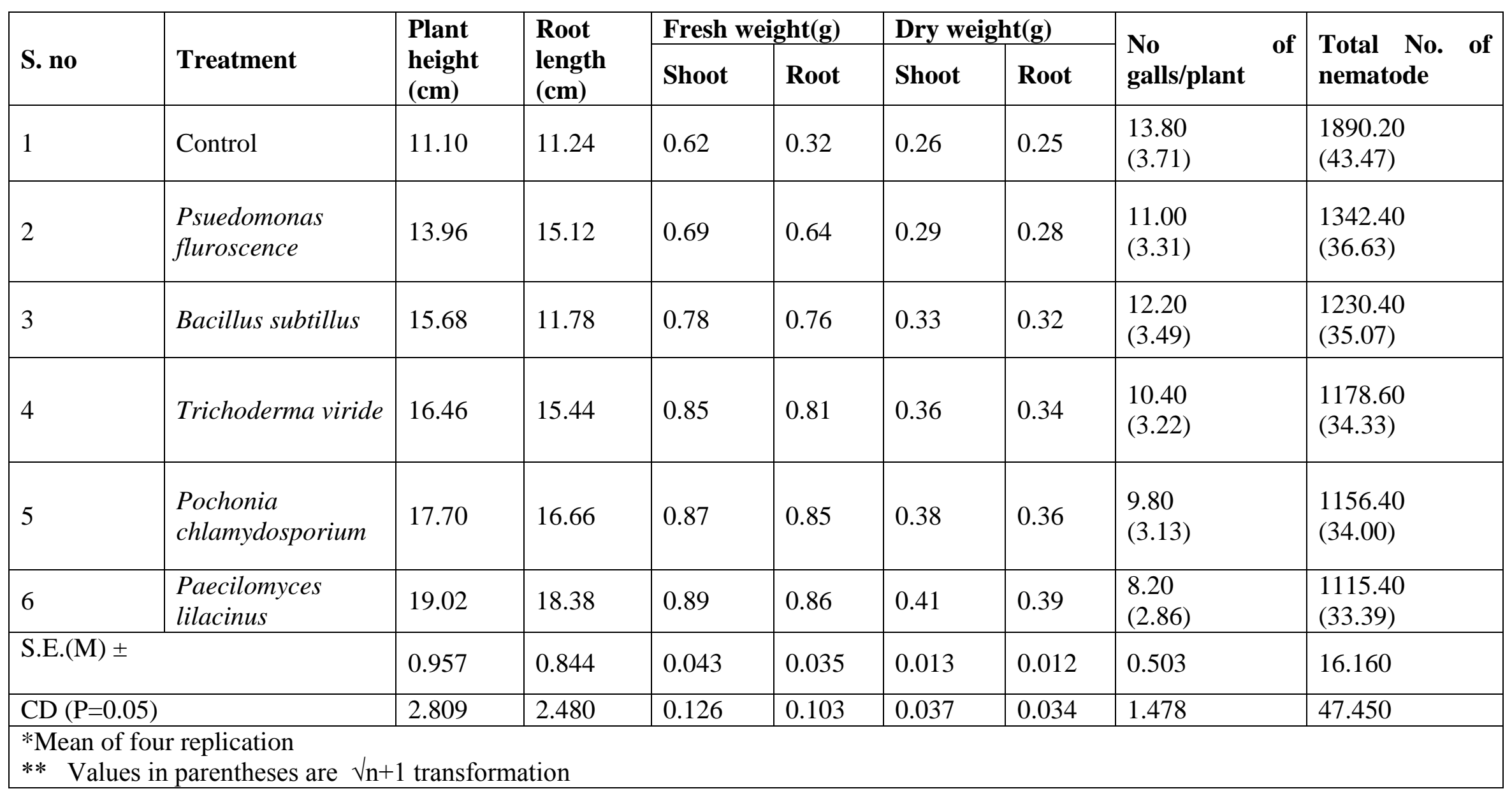


It can be concluded that the Paecilomyces lilacinus significantly increase the growth parameters of the black gram viz., plant height, root length, fresh and dry weight of shoot and roots with significant decrease in the number of galls and final nematode population. Pochionia chlamydosporia was also noted to be superior and took second rank in improving the plant growth and reduced nematode population. The egg parasitic Paecilomyces lilacinus and Pochionia chlamydosporia were found to have a significant effect in reducing galls and enhancing plant growth.

\section{Acknowledgement}

The authors are thankful to the Dean, College of Agriculture, Jawaharlal Nehru Krishi Vishwa Vidyalaya Jabalpur for providing necessary facilities and permission to conduct the study.

\section{References}

Akhtar, A., Abbasi, Hisamuddin, and R. Sharf. 2012. Antagonistic effects of Pseudomonas fluorescens and Bacillus subtilis on Meloidogyne incognita infecting Vigna mungo L. Inten. Animal and Environ. Sci., 2: 55-63.

Haseeb, A., Ahmad Vigar and P.K. Shukla. 2005. Comparitive efficacy of pesticides, biocontrol agents and botanicals against Meloidogyne incognita- Fusarium oxysporurn disease complex on Vigna mungo. Ann. Pl. Protec. Sci., 13: 434437.

Hussaini, S.S. and Seshadri, A.R. 1975. Interactionships between Meloidogyne incognita and Rhizobium spp. on mungbean. Indian J. Nematol., 5: 189199.

Karssen, G. and M. Moens. 2006. Root-knot nematodes. In: R.N. Perry and M. Moens, eds. Plant Nematol., Wallingford, UK: CABI Publishing, pp. 59-90.

Latha, T.K.S., E. Rajeswari and V. Narasimhan. 2000. Management of root-rot disease complex through antagonists and chemicals. Indian Phytopath., 53: 216218.

Mahapatra, S.N. \& P.K. Swain. 1999. Avoidable yield loss due to Meloidogyne incognita and Fusarium oxysporum in blackgram. Indian J. Nematol., 29: 87-89.

Mai, W.F. \& G.S. Abawi. 1987. Interaction among root-knot nematode and Fusarium wilt fungi on host plants. Ann. Rev. Phytol., 25: 317-338.

Poornima, K., Angappan, R., Kannan, N. Kumar, and T.N. Balanoha. 2007. Interactions of nematodes with the fungal Panama wilt disease of banana and its management. Nematol. Medite., 35: 3539.

Powell, N.T. 1971. Interactions between nematodes and fungi in disease complexes. Annu. Rev. Phytopath., 9: 263-274.

Siddiqui, Z.A. and I. Mahmood. 1995. Management of Meloidogyne incognita race 3 and Macrophornina phaseolina by fungus culture filtrates and Bacillus subtills in chickpea. Fundamental and Appl. Nematol., 18: 71-76.

Verma, A.C., H.K. Singh, and M. Nehal Khan. 2005. Management of root-knot nematode, Moloidogyne incognita through antagonistic approaches in pointed gourd. Indian J. Nematol., 35: 7879.

\section{How to cite this article:}

Dilip Kumar, Jayant Bhatt and Ratan Lal Sharma. 2017. Efficacy of Different Bio Control Agents against Meloidogyne incognita and Fusarium oxysporum on Black gram (Vigna mungo L). Int.J.Curr.Microbiol.App.Sci. 6(8): 2287-2291. doi: https://doi.org/10.20546/ijcmas.2017.608.268 